\title{
DRIVER COMPETENCE PERFORMANCE INDICATORS USING OTMR
}

\author{
Rawia Ahmed Hassan EI Rashidy, Coen van Gulijk \\ Institute of Railway Research (IRR), University of Huddersfield
}

\begin{abstract}
The current practice for assessing driver competence performance is in-cab riding by driver managers. However, this paper investigates whether real-world driving data extracted from on-train monitoring recorders data (OTMR) can be used to assess the driver performance. A number of indicators were used to evaluate the drivers' performance. These include: their use of the emergency bypass switch, the driver's reminder appliance as well as the driver's reaction time.

A study case illustrated the applicability of OTMR data to estimate the proposed indicators, which suggests that the indicators can be useful in the driver management system in addition to the current indicators. Furthermore, the proposed indicators could be used to tailor the driver training schemes up to their individual needs and evaluate their effectiveness. They could even be used for improving driver competence performance and reducing crash involvement by revealing potentially detrimental driving performance.
\end{abstract}

\section{Introduction}

OTMR are used to collect data about the way trains are driven and the state of various train systems during its journey. Examples of data collected include power and brake controller position, driver acknowledgement of signalling system warnings, whether the doors are open and the operation of driver's reminder appliance and the emergency bypass switch systems. The OTMR data is currently used in:

- incident/accident investigation, for example, beside other sources, OTMR is reviewed for a double signal passed at danger (SPAD) incident at Esher on 25 November 2005 (DfT, 2007),

- automated train condition monitering, for example, TAPAS condition monitoring system processes data recorded by OTMR to identify the required maintenance for trains (Green et al., 2001),

- automated driver assessment, for example, TAPAS and Churros process OTMR data to estimate a number of speed indictors sush as .the speed at which power notch 4 is selected when accelerating.

This paper extends the use of OTMR data in driver assessment to addres another issues such as drivers' use of safety systems as required by the Rule Book (GE/RT8000/TW5, 2014) as well as to estimate the driver's reaction time.

\section{Literature review}

\subsection{Human factor}

Elms (2011) and Feldmann et al. (2008) suggested that human factors represent the central part in rail safety. However, RSSB (2009) identified that accidents are multifactorial; 2283 incident factors were the cause of the 292 events analysed (an average of 8 factors per event), reflecting the multi-causal nature of incidents.

In general, individual attitudes are reflected by compliance to procedures, effective thinking when facing an unforeseen situation, and management aspects for a good safety attitude (Sorensen, 2002). According to HSE (2009), human failures could be classified 
into two categories, viz. human errors and violation. Both types may lead to an undesirable outcome. However, the first is when an intended decision or action deviates from an accepted standard and the latter is a deliberate deviation from rules, procedures, instructions and regulations. According to Flin et al. (2008), human errors are inevitable but all potential consequences need to be managed and mitigated by some non-technical skills (NTS) such as rule compliance, situation awareness and effective communication. The Office of Rail and Road (ORR, 2013) reported that one of the train operating companies linked the causes of its SPAD cases during 2010 to deficiencies in areas related with NTS such as lack of situational awareness and conscientiousness. Furthermore, following the introduction of non-technical skills training, Canadian Pacific Rail achieved a 46\% reduction in human-caused incidents and recorded the lowest incident rate for class 1 railways in North America (ORR, 2012). Furthermore, a continuous assessment of drivers could have a positive impact on rail safety as individuals' behaviour could be positivity influenced by being aware they are monitored (Wouters and Bos, 2000).

\subsection{Train driver performance indicators}

Despite the availability of massive source of data, i.e. OTMR, to date, there has been very little research to investigate train driver performance based on such data. Green et al. (2001) presented a number of performance indicators to facilitate the automatic analysis of driver performance. These indicators are: the speed at which power notch 4 is selected when accelerating, the percentage of time in a braking sequence that the driver selects brake step 3, the speed over Train Protection and Warning System (TPWS) grids approaching a Permanent Speed Restriction (PSR), the speed through a PSR as a percentage of the maximum speed and the mean speed when the automatic warning system (AWS) horn is received. The indicators are compared with average performance of the whole population of train drivers to assess an individual's driving performance in relation to the cohort of drivers using TAPAS and Churros software. Furthermore, Churros software shows individual events when a driver has made an error such as wrong-side door release and TPWS brake demand. The indicators used by TAPAS and Churros reflect the important issues in driver assessment process. However, in this paper, another group of indicators are suggested to enhance the assessment of the train driver performance, for example, drivers' use of safety systems as well as drivers' reaction time. The following subsections introduce the proposed indicators and highlight the importance of each one.

\subsection{Use of Safety systems}

The Rule Book (GE/RT8000/TW5, 2014) emphasises the responsibility of the driver to set a number of safety systems such as Emergency Bypass Switch (EBS), Driver's Reminder Appliance (DRA) and TPWS soon after entering the driving cab, stopped at station, and leaving the driving cab stages. Even so, in some cases drivers may switch off a safety system, for example, the initial investigation of the incident near Doncaster on 2 October 2015 found that staff on-board locomotive 45231 turned-off its TPWS (Railway Herald, 2015).

Despite the importance of use of safety systems, there is no mechanism to continuously monitor the use of these systems during train journeys. A number of Train operating companies use in cab assessment to monitor drivers' operational usage of DRA (McCorquodale et al., 2002). In research level (RSSB, 2004), digital cameras were implemented to record driver's action. Both previous techniques (in-cab assessment and in cab-observations) have their own merits in assessing the driver performance as they supplied comprehensive details about the driver performance. However, drivers may behave differently under observation, limiting the potential for indpendent driver 
assessment. Add to that, the time and money cost for both techniques hinders their use for continuous monitoring.

The use of OTMR data alternatively offers a continuous cheap source for monitoring the use of safety systems without distracting drivers. Up till now, the data related to the safety systems in OTMR are only reviewed in case of incident or accident. Including the use of safety systems in the assessment of the train drivers may enhance the rail safety.

\subsection{Driver reaction time}

Driver's reaction time has a potential effect on their competence level due to its practical implications. For example, the driver has to acknowledge safety system massages, such as TPWS horn within around 2.5 second to avoid an error leading to a braking application. Longer reaction time is also related to the driver fatigue level (Dorrian et al., 2007; Ji et al. 2004).

Furthermore, instance acknowledgment of safety system massages (i.e. driver acknowledges TPWS horn in less than 0.1 second) is also a bad practice as it could indicate unconscious response (Crick et al., 2004). Instance response also refers to "predict and act" behaviour which could have a further implication as discussed in Walker (2015). Previous studies (e.g. Crick et al.2004; Mcleod et al., 2004) implemented a number of methods such as in-cab observation, retrospective analysis and focus groups to estimate the average reaction time of drivers. Despite the effectiveness of these methods in estimating the average value of reaction time and highlight the common issues, they do not show the variation in the individual driver reaction time. Furthermore, they are not designed to introduce a continuous indicator for driver reaction time. To avoid this shortage, this research has implemented OTMR data to estimate the driver reaction time. By doing so, the extreme values, i.e. instance and late responses for each driver will be identified, hence required driver training could be conducted.

\section{Method}

Figure 1 presents the three steps used to estimate the proposed indicators. In the OTMR raw data stage, an algorithm has been developed to convert OTMR data format to CSV files format. The main purpose is to be able to handle multi files in $\mathrm{R}$ software and save tremendous time of data analysis and plotting. The initial handling of data stage examines data types and format. Furthermore, closer inspection of data shows a number of deficiencies that can affect the reliability of data analysis such as missing values across all the variables and unknown or unexpected character encoding. To automate the correction of data type and format, an $\mathrm{R}$ script is written and checked against a manual calculation using Excel. Figure 2 gives an example of changing "Time" and "Relative Time" format to facilitate the use of both variables in the data analysis stage.

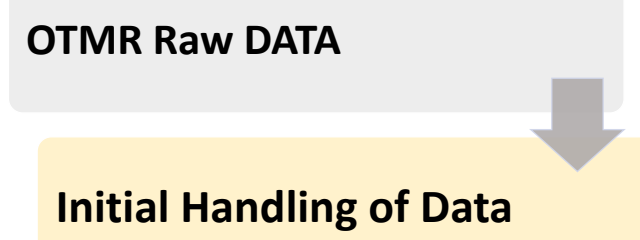

\section{OTMR Data Analysis}

Figure 1 Steps used to estimate the proposed indicators. 


\begin{tabular}{|l|l|}
\hline Time & Relative Time \\
\hline $06 / 11 / 1218 \mathrm{~h} 41 \mathrm{mn} 38 \mathrm{~s} 2$ & $00 \mathrm{~s} 0$ \\
\hline $06 / 11 / 1218 \mathrm{~h} 41 \mathrm{mn} 38 \mathrm{~s} 3$ & $+00 \mathrm{~s} 1$ \\
\hline $06 / 11 / 1218 \mathrm{~h} 41 \mathrm{mn} 38 \mathrm{~s} 3$ & $+00 \mathrm{~s} 1$ \\
\hline $06 / 11 / 1218 \mathrm{~h} 41 \mathrm{mn} 38 \mathrm{~s} 3$ & $+00 \mathrm{~s} 1$ \\
\hline $06 / 11 / 1218 \mathrm{~h} 41 \mathrm{mn} 38 \mathrm{~s} 5$ & $+00 \mathrm{~s} 3$ \\
\hline $06 / 11 / 1218 \mathrm{~h} 41 \mathrm{mn} 38 \mathrm{~s} 5$ & $+00 \mathrm{~s} 3$ \\
\hline $06 / 11 / 1218 \mathrm{~h} 41 \mathrm{mn} 38 \mathrm{~s} 6$ & $+00 \mathrm{~s} 4$ \\
\hline $06 / 11 / 1218 \mathrm{~h} 41 \mathrm{mn} 38 \mathrm{~s} 7$ & $+00 \mathrm{~s} 5$ \\
\hline $06 / 11 / 1218 \mathrm{~h} 41 \mathrm{mn} 38 \mathrm{~s} 7$ & $+00 \mathrm{~s} 5$ \\
\hline
\end{tabular}

a) Initial time and relative time format.

\begin{tabular}{|c|r|}
\hline \multicolumn{1}{|l|}{ Time } & Relative. Time \\
\hline $06 / 11 / 201218: 41: 38.2$ & 0 \\
\hline $06 / 11 / 201218: 41: 38.3$ & 0.1 \\
\hline $06 / 11 / 201218: 41: 38.3$ & 0.1 \\
\hline $06 / 11 / 201218: 41: 38.3$ & 0.1 \\
\hline $06 / 11 / 201218: 41: 38.5$ & 0.3 \\
\hline $06 / 11 / 201218: 41: 38.5$ & 0.3 \\
\hline $06 / 11 / 201218: 41: 38.5$ & 0.4 \\
\hline $06 / 11 / 201218: 41: 38.7$ & 0.5 \\
\hline $06 / 11 / 201218: 41: 38.7$ & 0.5 \\
\hline
\end{tabular}

b) Corrected time and relative time format.

Figure 2 Time and relative journey time variables.

In this paper, EBS and DRA are chosen as an example of safety systems that the driver has to apply. The use of EBS is monitored for the entire journey, whereas the driver has to set DRA at every red signal experienced, as required by the Rule book (GE/RT8000/TW5, 2014). Furthermore, the driver reaction time is evaluated based on the time taken to cancel the TPWS horn as a proxy measure, i.e. horn and acknowledgment.

In OTMR data analysis stage, a number of OTMR channels are used to extract the relevant scenarios as presented in Table 1. For example, zero speed periods are calculated based on the train speed. The door release channels are, then, examined to determine if the train is stopped in a station or in front of a red signal, followed by a check of DRA channels.

\begin{tabular}{|c|c|}
\hline Situation & OTMR Channels \\
\hline Use of EBS & $\begin{array}{l}\text { - EBS channels, } \\
\text { - Relative time channel. }\end{array}$ \\
\hline Consistent use of DRA when facing a red signal & $\begin{array}{l}\text { - DRA channels, } \\
\text { - Speed channel, } \\
\text { - Door-release channels. } \\
\text { - Relative time channel. }\end{array}$ \\
\hline Reaction time & $\begin{array}{l}\text { - TPWS channels, } \\
\text { - Relative time channel. }\end{array}$ \\
\hline
\end{tabular}

Table 1 Detecting different situations using OTMR channels.

An algorithm is developed in $\mathrm{R}$ environment to extract the required scenarios from OTMR data files and to estimate the use of DRA and EBS in addition to calculating the driver reaction time.

\section{Study case}

\subsection{Data}

The OTMR data files used in this paper were supplied by Southern Railway. They are for the same route and the same day but different drivers to eliminate the impact of route conditions. The steps explained in Section 3 are implemented to estimate the proposed indicators. 


\subsection{Results and discussion}

\subsubsection{Use of EBS and DRA}

The analysis of OTMR files shows that $100 \%$ of OTMR data files comply with EBS use. Figure 3 shows the number of the red signals drivers experienced during each journey and the corresponding use of DRA, indicating that all drivers complied with the rules except for Journey 6 . The Journey 6 driver experienced 4 red signals but set the DRA 3 times. Consequently, a further analysis has been carried out to confirm these findings. Figure 4 presents the train speed, door release (left hand side and right hand side of cab in use), and DRA use of Journey 6. The driver did not set the DRA for the first red signal he/she experienced, indicated with the red circle in Figure 4, whereas set it for the rest of red signals, shown in the blue circle in Figure 4. The driver also used the DRA when stopped at station 10, suggesting that the driver faced a red signal at the end of the platform. It should be noted that, the data from OTMR journey files can confirm the driver set the DRA in case of red signal at the end of the platform as required by the Rule Book. However, if the driver does not set the DRA in case of a red signal at the end of the platform, OTMR channels cannot detect this error as such scenario cannot be identified by OTMR data only.

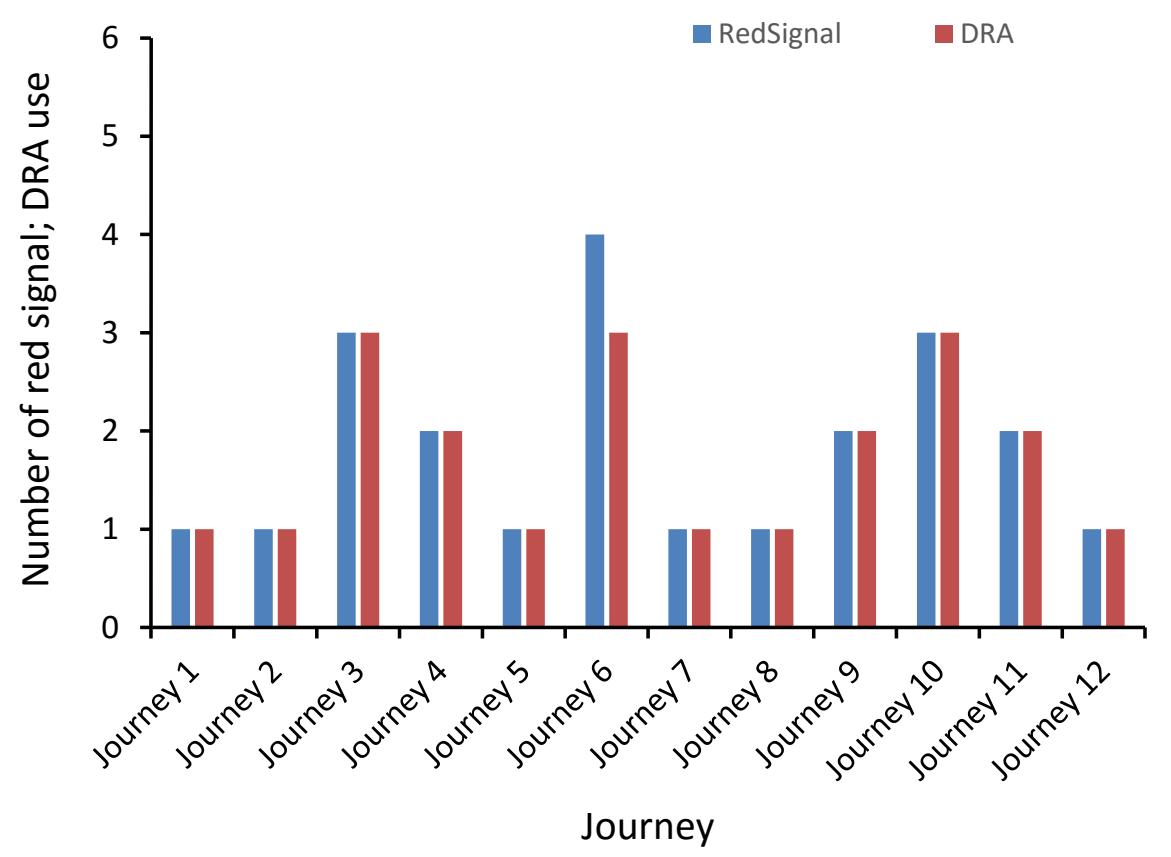

Figure 3 Number of red signals drivers experienced during each journey and the corresponding use of DRA. 


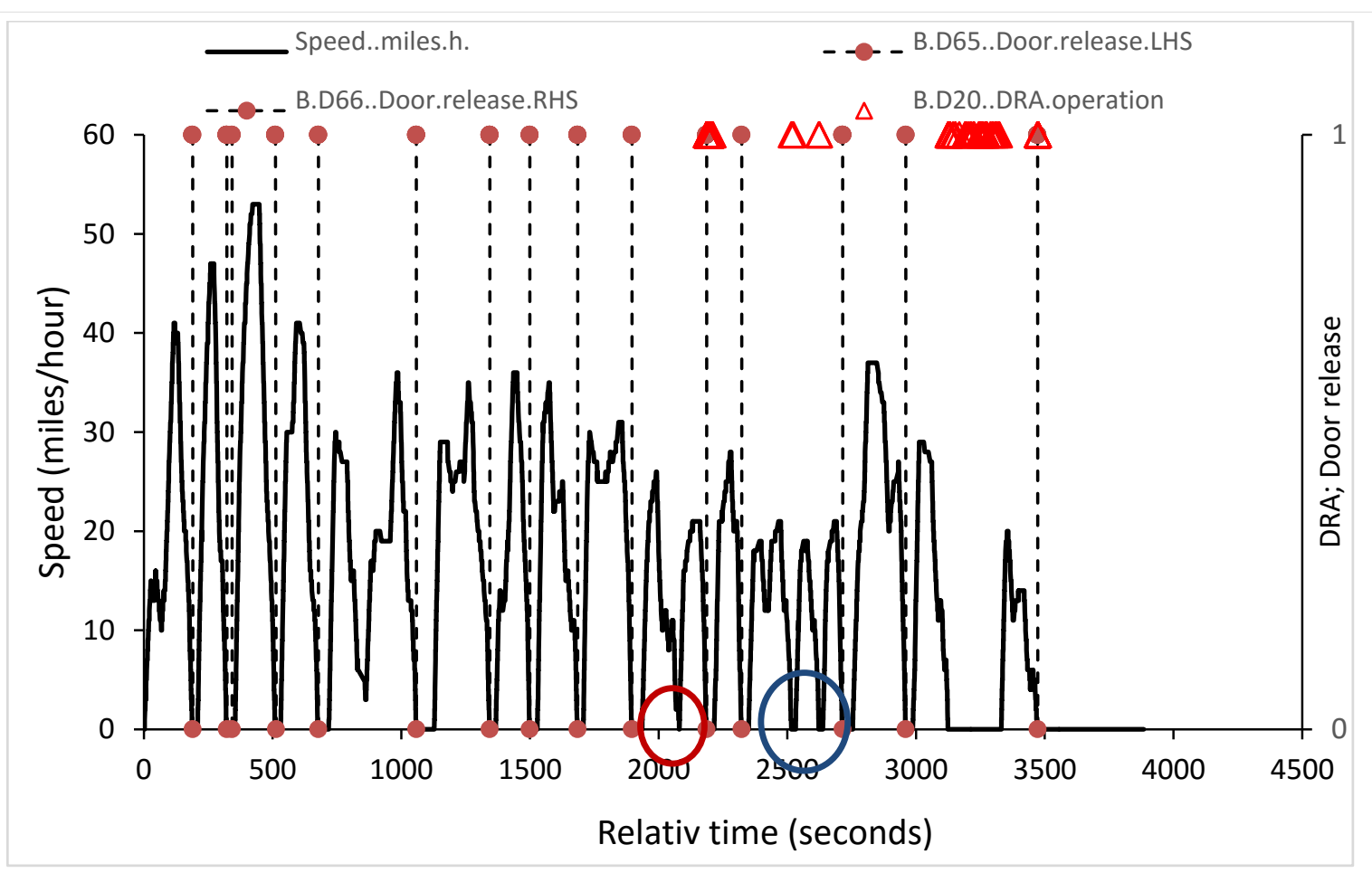

Figure 4 Train speed, door release and DRA use for Journey 6.

\subsubsection{Driver's reaction time}

Box plots, presented in Figure 5, are used to show driver's reaction time variability during a journey in addition to the variation among drivers. All the drivers are in compliance with the max reaction time (i.e. less than 2.2 seconds) as the maximum value is around 1.4 seconds as presented in Figure 5. In general, Figure 5 shows a wide variation in reaction time patterns, but it is observed the majority of the drivers have the reaction time below 0.6 second, that is lower than 0.6-0.9 seconds average reaction time suggested by other studies (Scott, 2008; Crick et al.2004; Mcleod et al., 2004). Furthermore, 8 drivers out of 12 have a minimum of zero reaction time (less than 0.1 second, the interval of OTMR data recording) at least once during their journey. These values suggested that the drivers may consider acknowledgment of TPWS horn as a high priority task to avoid TPWS brake demand which is classified as an error. However, very quick response could indicate the unconscious cancelling of warning signs as stated by RSSB (2004) and, in such case, there is a need to be addressed by a suitable training.

In terms of individual driver, for example, in journey 10, the box plot is extremely short, indicating that the driver's reaction time is nearly constant with a value around 0.2 seconds. In contrast, Journey 2 has a longer box plot, suggesting a wider variation in the driver reaction times during the journey. Furthermore, the minimum reaction time is equal to zero whereas the highest reaction time is equal to 1.4 seconds. 


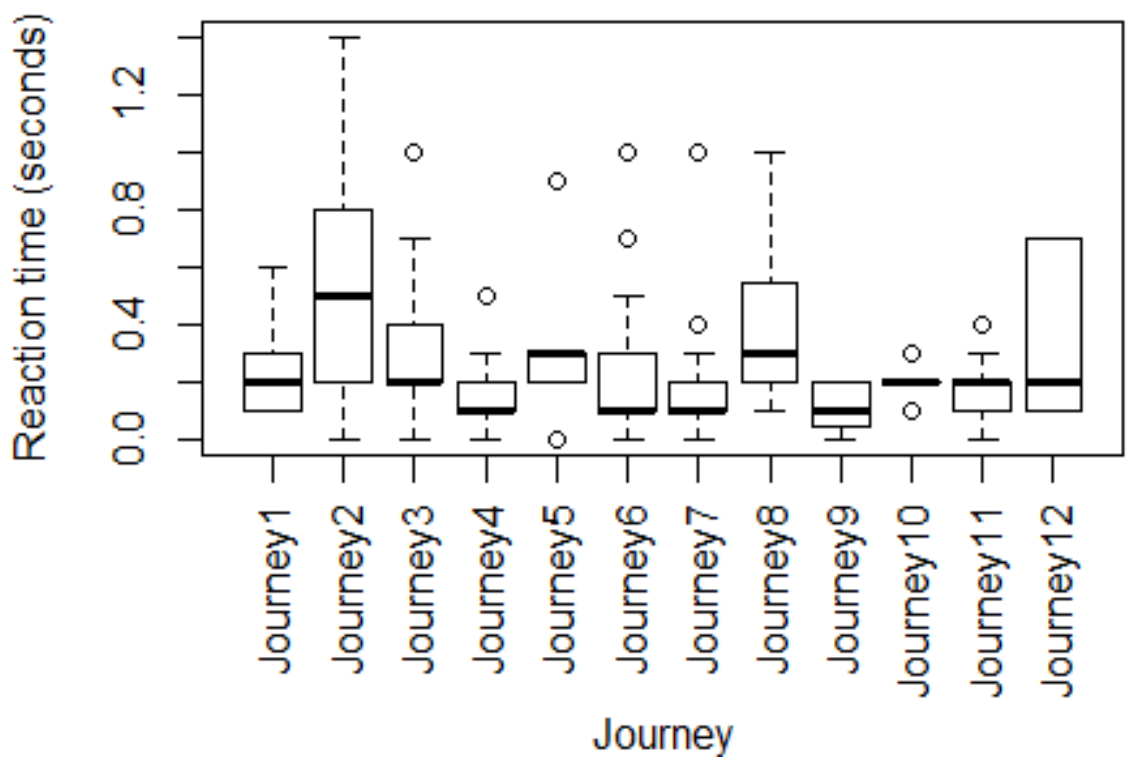

Figure 5-Drivers' reaction time.

\section{Conclusions}

This paper proposed a number of driver performance indicators based on real-world driving data extracted from OTMR data files. The use of safety systems such as EBS and DRA and the driver reaction time are proposed.

The study case illustrated the applicability of the proposed indicators. Assessing drivers performance based on real-world driving data offers a fair method for continuous assessment of drivers performance under real life conditions. Besides, it could be used to develop the required training scheme for drivers based on their driving data.

\section{Acknowledgements}

This work was funded by the Rail Safety and Standards Board (RSSB).

\section{REFERENCES}

CRICK, J.L., CHAPPELOW, J., CLARK, J., LEAR, A., MCCORQUODALE, B., O'CONNOR, E.and PAGE, H. (2004). Driver Error Data Collection Project: Report on Work package 01. QinetiQ Technical Report: Qinetiq/KI/CHS/TR032575/2.0, QinetiQ, Farnborough.

DfT, Department for Transport. (2007). Autumn Adhesion Investigation Part 1: Signals WK338 and WK336 Passed at Danger at Esher 25 November 2005. Report 25 (Part 1)/ 2006-January 2007.

DORRIAN, J., ROACH, G.D., FLETCHER, A. and DAWSON, D. (2007). Simulated train driving: Fatigue, self-awareness and cognitive disengagement. Applied Ergonomics, 38(2), pp. 155-166.

FELDMANN, F., HAMMERL, M. and SCHWARTZ S. (2008). Questioning human error probabilities in railways. The 3rd IET International Conference on System Safety, 20 -22 October 2008, NEC, Birmingham, UK.

FLIN, R., O'CONNOR, P. and CRICHTON, M. (2008). Safety at the sharp end: A Guide to Non-Technical Skills. Hampshire: Ashgate Publishing Limited.

GREEN, S.R., BARKBY, S., PUTTOCK, A. and CRAGGS, R. (2001). Automatically assessing driver performance using black box OTDR data. Railway Condition Monitoring 
and Non-Destructive Testing (RCM 2011), 5th IET Conference, pp.1-5, 29-30 Nov. 2001. HAS, The Health and Safety Authority, (2013). Behaviour based safety guide: doing what we do better, smarter, safer. HAS, the Health and Safety Authority, Dublin.

JI, Q., ZHU, Z., and LAN, P. (2004). Real-Time Nonintrusive Monitoring and Prediction of Driver Fatigue. IEEE TRANSACTIONS ON VEHICULAR TECHNOLOGY, VOL. 53(4), NO. 4, pp. 1052-1068.

KECKLUND, L., INGRE, M., KECKLUND, G., SÖDERSTRÖM, M., ÅKERSTEDT, T., LINDBERG, E. JANSSON, A., OLSSON, E. SANDBLAD, B. and ALMQVIST, P. (2001). The TRAIN - project: Railway safety and the train driver information environment and work situation. Signalling Safety 2001, 26-27 February 2001, London,

ORR, the Office of Rail and Road, (2012) Non-Technical Skills (NTS) for rail staff, and RSSB's NTS guidance (RGD-2012-03), ORR.

McCorquodale, B., CHISSICK, C., McGUFFOG, A., ROWLEY, I. and BUNTING, A. and Page, H. (2002) Driver's Reminder Appliance (DRA) effectiveness study : Final report, Qinetiq/KI/CHS/CAP/CR020937/2.0/2.0, QinetiQ, Farnborough.

MCLEOD, R., WALKER, G.H., MORAY, N. AND Love, G. (2003). Driver reliability with extended AWS. Project Summary Report.B/C271/FD.5. Nickleby HFE ltd. MCLEOD, R., WALKER, G.H., MORAY, N. AND MILLS, N. (2005). Analysing and modelling train driver performance. Applied Ergonomics, 36(6), pp. 671-680.

Railway Herald (2015). ORR issues prohibition notice on WCR. Available from: http://railwayherald.com/uknews/orr-issues-prohibition-notice-on-wcr[3 February 2016].

REASON, J., PARKER, D. and LAWTON, R. (1998). Organizational controls and safety: The varieties of rule-related behaviour. Journal of Occupational and Organizational, 71, pp.289-304.

RSSB, the Rail Safety and Standards Board, (2009). Management driver error data collection project: final report. RSSB.

RSSB, the Rail Safety and Standards Board, (2009). An analysis of formal inquiries and investigations to identify human factors issues: Human factors review of railway incidents. RSSB.

RSSB, the Rail Safety and Standards Board, (2013). Safety assurance guidance and examples of good practices in safety assurance in Britain's railway industry. RSSB.

RSSB, the Rail Safety and Standards Board, (2014a) Measuring safety and performance: how to develop and manage safety performance indicators for Britain's railway. RSSB. RSSB, The Rail Safety and Standards Board, (2014b) Measuring safety and performance: Case study 6: Train driving. RSSB.

Scott, A., (2008). Finger on your buzzers please. Contemporary Ergonomics 2008 Proceedings of the International Conference on Contemporary Ergonomics (CE2008), 1-3 April 2008, Nottingham, UK Edited by Bust, B.D., Taylor \& Francis 2008 Pages 583-588 WOUTERS, P.I.J. and BOS, J.M, J. (2000). Traffic accident reduction by monitoring driver behaviour with in-car data recorders. Accident Analysis \& Prevention, 32(5), pp. 643-650. 